\title{
RURALIDADES E TURISMO GASTRONÔMICO NO MUNICÍPIO DE SILVEIRA MARTINS, RS, BRASIL
}

\author{
Michele Lindner ${ }^{1}$, Suelen de Leal Rodrigues ${ }^{2}$, Marcelino de Souza ${ }^{3}$ \\ 1, 2 Universidade Estadual Paulista - UNESP - Rio Claro - SP - Brasil \\ 3Universidade Federal do Rio Grande do Sul - UFRGS - Porto Alegre - RS - Brasil
}

\begin{abstract}
Resumo: No debate académico o rural e o urbano ocuparam hoje um espaço relevante.A par, descortina-se uma inversão de valores relativos a estes dois espaços, mormente com a busca de uma vida mais saudável e com o contacto com a natureza, a que se associa a valorização da ruralidade.. Assim, o espaço rural, antes visto como o espaço apenas da produção agropecuária, é hoje usado comoárea de lazer e local de residência.

Aliás, é através da actividade de lazer e de ócio em áreas rurais que hoje podemos aferir a crescente procura pela tradição e pelo endógeno. Como refere Wandeley (2001), a sociedade brasileira reforça presentemente o seu olhar sobre o rural, antes visto como uma fonte de problemas, hoje indiciando um potencial de "soluções".
\end{abstract}

A busca pelos hábitos e elementos da vida no campo refletea concomitante procura pela atividade turística em áreas rurais. Entre as modalidades do turismo em área rural sublinhamos aqui oagroturismo, porquanto se trata de uma modalidade que mais enfoca as ruralidades locais e propicia ao visitante vivenciar e experenciar a vida rural.

Nessa perspectiva, procurou-se analisar a matriz enformadora do "rural tradicional"e a sua valorização como produto turístico em pequenos municípios no interior do Brasil. Ocase study propostoincide sobre o município de Silveira Martins, localizado na parte central do Estado do Rio Grande do Sul. Este município comporta uma Rota Gastronômicaque apresente elementos que reportam aos visitantes as tradições e a ancestralidade da imigração italiana que ao longo do século XIX se fixou na região.

A análise do estudo realizado no município de Silveira Martins - RS - baseou-se em dados obtidos através de entrevistas e questionários não estruturados aplicados no local, bem como na observação participante durante as visitas realizadas no Município e na análise de material de divulgação turística.

Palavras-Chave: Ruralidades; endógeno; turismo em espaço rural.

Abstract: Ruralities and food tourism in the municipality of Silveira Martins, RS, Brasil

In the academic debate rural and urban occupied a relevant space today. At the same time, a reversal of values for these two spaces is revealed, especially with the search for a healthier life 
and contact with nature, which is associated with the appreciation of rurality. Thus, rural areas, once seen as the area of agricultural production alone, are now used as a recreation area and place of residence.

Indeed, it is through leisure activity and leisure in rural areas that today we can gauge the growing demand for tradition and for the endogenous. As Wandeley (2001) refers, Brazilian society reinforces its present eye on the countryside, once seen as a source of problems, but today indicating a potential "solutions".

The search for the habits and elements of country life reflects the concomitant demand for tourism in rural areas. Among the modalities of tourism in rural areas, we emphasize here agritourism, because it is a discipline that focuses the most on local ruralities and enables the visitor to live and experience the rural life.

In that perspective, it was sought to analyze the formatting matrix the "traditional rural" and its appreciation as a tourist product in small towns in rural Brazil. The proposed case study focuses on the municipality Silveira Martins, located in the central part of the state of Rio Grande do Sul. This municipality includes a Gastronomic Route which features elements that report to visitors the traditions and ancestry of Italian immigration that settled in the region throughout the nineteenth century.

The analysis of the study conducted in the city of Silveira Martins - RS - was based on data obtained through interviews and unstructured questionnaires applied on site, as well as participant observation during the visits that took place in the city and in the analysis of tourist publicity material.

Keywords: Ruralities; endogenous; rural tourism

Resumen: Ruralidades y turismo gastronómico en el municipio de Silveira Martins, RS, Brasil

En el debate académico lo rural y lo urbano ocupan hoy un espacio relevante. Al mismo tiempo, se hace patente una inversión de los valores relativos a estos dos espacios, sobre todo con la búsqueda de una vida más sana y el contacto con la naturaleza, a la que se asocia la revalorización de lo rural. Así, el espacio rural, antes visto solamente como un ámbito de producción agropecuaria, es hoy utilizado como zona de recreo y lugar de residencia.

De hecho, es a través de actividades de ocio y esparcimiento en las áreas rurales como hoy podemos calibrar la creciente demanda de la tradición y lo endógeno. Como indica Wandeley (2001), ahora la sociedad brasileña refuerza su mirada sobre lo rural, antes visto como una fuente de problemas, y hoy como un potencial de "soluciones".

La búsqueda de los hábitos y elementos de la vida en el campo se refleja en la concomitante demanda de actividad turística en áreas rurales. Dentro de los tipos de turismo en esas áreas, destacamos aquí el agroturismo, porque se trata de la modalidad que más enfoca las ruralidades locales y propicia que el visitante viva y experimente la vida rural.

Desde esa perspectiva, se ha buscado analizar la matriz conformadora del "rural tradicional" $y$ su revalorización como producto turístico en los pequeños municipios del interior de Brasil. El estudio de caso propuesto se centra en el municipio de Silveira Martins, localizado en la parte central del estado de Rio Grande do Sul (RS). Este municipio cuenta con una ruta gastronómica que presenta elementos que dan a conocer a los visitantes las tradiciones y los atavismos de la inmigración italiana que se estableció en la región a lo largo del siglo XIX.

El análisis del estudio llevado a cabo en el municipio de Silveira Martins -RS- está basado en datos obtenidos a través de entrevistas y cuestionarios no estructurados aplicados en el lugar, así como en la observación participante durante las visitas al municipio y el análisis de material turístico publicitario.

Palabras clave: Ruralidades, endógeno, turismo rural 


\section{TURISMO EM ÁREAS RURAIS E RURALIDADES}

O turismo rural despontou enquanto atividade de destaque no meio rural, primeiramente em países da Europa, surgindo depois em outros países. Tulik (2003), afirma que na maioria dos países que seguem as diretrizeseuropéias, a denominação "Turismo Rural" é usada para referir-se a qualquer forma de turismo. Já no caso brasileiro, alguns autores preferem usar, para a totalidade das atividades turísticas nas áreas rurais, a denominação Turismo em Espaço Rural ou Turismo em Áreas Rurais, deixando a expressão Turismo Rural apenas para as atividades que levam em conta as especificidades da vida e das atividades rurais.

Ressalta-se que, devido à grande diversidade de termos, o turismo adquire características de acordo com cada configuração socioespacial. Ao invés de falar em turismo rural, o correto seria falar em um conjunto de práticas turísticas em espaço rural. Assim, Portuguez (2002), em seu trabalho, considerou conveniente utilizar o termo "turismo em espaço rural", pelo fato de ser abrangente, pois o agroturismo adquiriu uma infinidade de feições que, por vezes, confundem-no com modalidades diversas. Assim, segundo o mesmo autor, o turismo rural foi definido como:

"um conjunto de modalidades, que consiste na atração de demanda eminentemente interna e citadina para os ambientes rurais, em que os turistas podem experimentar maior contato com o ambiente bucólico, bem como com os costumes locais e o dia-a-dia da vida no campo" (Portuguez, 2002, p.76-77).

Porém, é necessário fazer distinções entre as diversas práticas de turismo em espaços rurais, pois, por exemplo, pode-se praticar turismo ambiental em espaço rural, e este não ser especificamente dentro de uma propriedade. Tulik (2003) apresenta em seu trabalho as classificação mais comuns de turismo em espaço rural: Turismo Rural; Turismo Alternativo; Turismo no Espaço Rural (TER) ou Turismo nas Áreas Rurais (TAR); Turismo em Áreas Rurais e Naturais; Turismo na Natureza/ Turismo Rural/ Ecoturismo; Turismo Cultural; Agroturismo.

Turismo Rural representa o conjunto de atividades desenvolvidas no espaço rural, porém muitos autores não concordam com essa expressão genérica, pois questionam se tudo que existe nessa área é de fato rural, e colocam que o termo Turismo Rural deveria estar ligado às características próprias do meio rural; Turismo Alternativo, essa distinção se aplica ao turismo como um todo, sendo baseada na pressão ambiental do turismo, representando uma oposição ao Turismo Convencional, principalmente o litorâneo, internacional e massificado; Turismo no Espaço Rural (TER) ou Turismo nas Áreas Rurais (TAR), é empregada como sinônimo do Turismo Rural, possui um sentido amplo e representa o aproveitamento turístico de um conjunto de elementos do espaço rural, rurais, culturais e elementos da natureza; Turismo em Áreas Rurais e Naturais constitui uma variação do TER/TAR, parte-se do impacto ambiental do turismo de massa para chegar ao Alternativo e demonstra que o Turismo Rural além de espaços rurais, engloba áreas naturais onde se desenvolve o Ecoturismo; Turismo na Natureza/ Turismo Rural/ 
Ecoturismo, o Turismo Rural ligado a natureza é uma linha observada na literatura, é colocado por alguns autores como uma das variantes do Turismo na Natureza, assim como este pode estar vinculado ao Turismo Ecológico. Essa mescla do Turismo Rural com o Ecoturismo esta ligado a dificuldade de se estabelecer limites precisos entre eles, pois muitas vezes ocorrem em uma mesma propriedade; Turismo Cultural, esta inserido no Turismo Rural, devido ao conteúdo cultural que impregna este, porém destaca-se que todo turismo tem uma base cultural; Agroturismo, para muitos autores é entendido como atividade que ocorre numa propriedade com exploração agrícola e criação de gado, representando um complemento na renda do proprietário e das atividades da propriedade, com gestão familiar, alojamento na propriedade, contatodireto do visitante com o meio rural, através da participação nas atividades da propriedade ou através da compra de produtos locais (Tulik, 2003).

Portuguez (2002, p.77) coloca que o agroturismo pode ser entendido como:

"a modalidade de turismo em espaço rural praticada dentro das propriedades, de modo que o turista e/ou excursionista entra, mesmo que por curto período de tempo, em contato com a atmosfera da vida na fazenda, integrando-se de alguma forma aos hábitos locais" (Portuguez, 2002: 77).

Dessa forma, o turista passa a vivenciar os modos de vida do rural, ou seja, a expressão das ruralidades presentes naquele local. A temática "ruralidades" atualmente tem sido um tema muito discutido no contexto acadêmico, portanto para que se possa ter bem claro o que se quer dizer ao falar em "ruralidades" no caso desse estudo, torna-se necessário ter claro o seu significado.

Dessa forma buscou-se o trabalho de Candiotto e Corrêa (2008), que ao discorrer sobre o conceito de ruralidades colocam que este esta assentado em duas correntes de interpretação. Segundo a pesquisa dos autores, a primeira corrente vê a ruralidade como um processo de valorização do rural, a qual vem sendo disseminada por instituições globais através de financiamentos e políticas publicas. Essas instituições defendem o discurso da redução da pobreza e desigualdades sociais, porém segundo os autores está implícito nesse discurso a ampliação das relações capitalistas, através de novas atividades agrícolas e não agrícolas no espaço rural.

Nessa perspectiva, a nova ruralidade não é algo construído socialmente pela população rural, mas mais uma idéia imposta por organismos concentradores do poder, cristalizada no discurso, porém muitas vezes não concretizada, que passa a ser utilizada e propagada por diversos pesquisadores como novos aspectos da realidade do espaço rural (Candiotto e Corrêa, 2008: 232).

A segunda corrente coloca as ruralidades como realidade empírica, construída, sobretudo de forma endógena. "As ruralidades seriam compostas por objetos, ações e representações peculiares do rural, com destaque para as representações e identidades rurais dos indivíduos e grupos sociais" (Moreira, 2005, apud Candiotto e Corrêa, 2008: 233).

Dessa forma, o que permitirá falar em ruralidades são as articulações entre as noções de rural e de identidade social, relações especificas dos habitantes do campo com a natureza e sua comunicação direta, face a face (Moreira; Gaviria, 2002). 
Mesmo representando as relações especificas dos habitantes do campo, Carneiro (1998 apud Candiotto e Corrêa, 2008) coloca que a ruralidade não é definida como oposição a urbanidade, ela é um processo dinâmico em constante reestruturação de valores locais, hábitos e técnicas, incorporados a partir da relação entre campo e cidade.

Segundo Candiotto e Corrêa (2008), alem da população rural, a urbana também apresenta suas ruralidades, as quais são idealizadas pela mídia que vende o rural como sinônimo de natureza e vida mais saudável. Assim como a população rural possui urbanidades devido a incorporação dos valores urbanos, seja por meio da televisão ou da internet. Nesse sentido, os autores citam Lima (2005), que coloca que existem elementos da ruralidade no urbano, assim como da urbanidade no rural.

E é com base nessas ruralidades, que expressam os costumes e modos de vida tradicionais da população local, encontradas tanto nas áreas rural como urbana do município de Silveira Martins, que esse estudo baseia sua análise. As ruralidades identificadas no Município passaram a representar também a oferta do atrativo turístico dessa localidade, que explora antigos costumes dos antepassados que colonizaram a região, reproduzidos ainda hoje no cotidiano de muitas famílias da localidade, expressos principalmente nas festividades e gastronomia.

\section{A EXPLORAÇÃO TURÍSTICA DO RURAL TRADICIONAL NO MUNICÍ- PIO DE SILVEIRA MARTINS - RS}

O município de Silveira Martins está situado na região central do Estado do Rio Grande do Sul (Figura 1). Sua área encontra-se situada sobre a Serra de São Martinho, na Serra Geral, ou Rebordo do Planalto, é uma das áreas piloto da Reserva de Biosfera da Mata Atlântica no Estado, apresentando clima subtropical húmido.

O Município tem sua origem na década de 70, no século XIX, quando o Governo Imperial requisitou as terras devolutas existentes na região de Santa Maria da Boca do Monte e, nelas, instalou o Quarto Núcleo de Colonização do Estado. Os primeiros habitantes deste núcleo foram russos e alemães, que na sua grande maioria abandonaram a região por não se adaptarem às condições geográficas das encostas da Serra São Martinho. Este fato levou a direção da colônia a desviar levas de imigrantes italianos para povoar aquela região (RUVIARO, 2007). 
Figura 1 - Localização do Município de Silveira Martins em relação ao Estado do Rio Grande do Sul

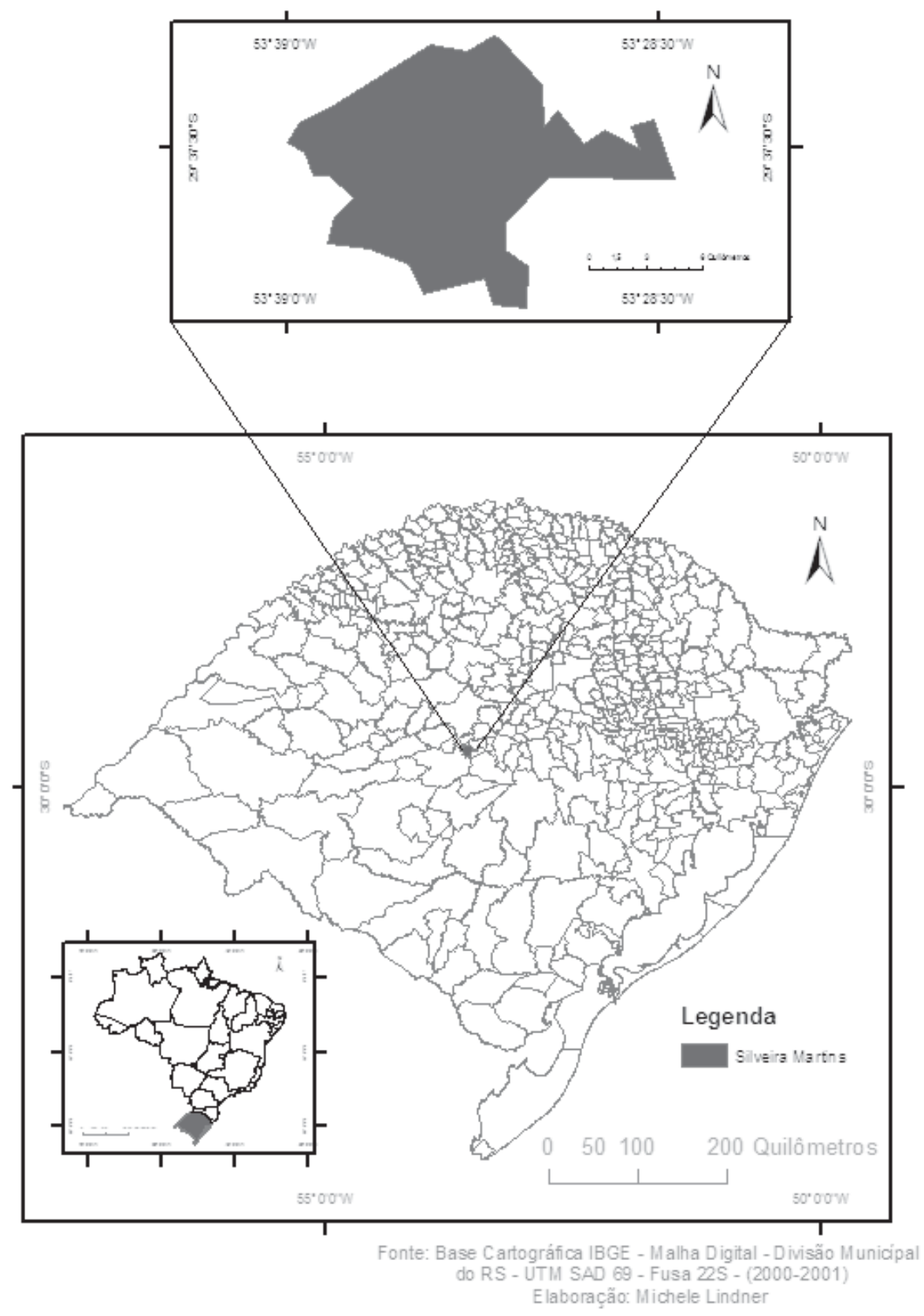

Assim a Quarta Colônia de Imigração Italiana como o próprio nome já diz foi o quarto núcleo de colonização que recebeu imigrantes italianos e seus descendentes no 
Estado do Rio Grande do Sul. A imigração italiana e de descendentes de imigrantes para colonizar a área da Região da Quarta Colôniaé explicada pela literatura, referente a história da região, pelo fracasso da colonização de russos e alemães nessa área, o que fez com que o Governo da Província de São Pedro (Rio Grande do Sul) tomasse medidas para promover o Novo Núcleo de Povoamento, Silveira Martins.

A colonização italiana no estado do Rio Grande do Sul tem suas origens no ano de 1869 quando a Província requisitou duas glebas do Império para continuar o processo de colonização iniciado anteriormente com a vinda de imigrantes alemães. As glebas foram concedidas em 1870 e no dia 24 de maio desse ano o presidente da Província criava as colônias de "Conde d'Eu" e "Dona Isabel", em homenagem ao Príncipe Consorte e a herdeira do trono. A data oficial da imigração italiana é de 20 de maio de 1875, mas não se sabe ao certo em que data o império tomou a si a incumbência de colonizar Conde d'Eu e Dona Isabel. Destaca-se que o intuito do Governo Imperial ao assumir a colonização dessas Colônias era de uma colonização propaganda, que atraísse imigrantes ao Brasil, onde a crise da mão-de-obra agravava-se com o movimento abolicionista. Em 1875 o Governo Imperial cria mais uma colônia, a Fundos de Nova Palmira, em 11 de março de 1877, o nome da colônia é modificado passando a chamar-se de "Colônia Caxias" (Boni; Costa, 1982).

Em 1877 o governo resolveu criar então uma quarta colônia para imigrantes italianos, utilizando áreas de mata próximas a Santa Maria, surgindo assim a Colônia de Silveira Martins. "Estas 4 colônias foram o núcleo básico da imigração italiana, sendo que as outras , de certa forma, delas promanaram" (Boni; Costa, 1982: 65).

A Colônia de Silveira Martins não limitava-se ao território do município que leva este nome,alem deste englobava os municípios atuais de Faxinal do Soturno, Nova Palma, Ivorá, São João do Polêsine, Pinhal Grande, parte dos municípios de Dona Francisca, Restinga Seca e áreas pertencentes a Santa Maria e Julio de Castilhos.

Os primeiros imigrantes (157 famílias somando 462 pessoas) chegaram a Silveira Martins, no barracão Val de Buia, em setembro de 1877. Até o final deste ano vieram mais três grupos, permanecendo no barracão até a demarcação das terras. Primeiramente, foi difícil a adaptação a terra desconhecida, após vieram as colheitas e as mesas fartas e o apego surgido a nova terra (Santin, 1999).

De acordo com Santin (1999), das quatro colônias de imigração italiana no Rio Grande do Sul, a primeira colônia a se tornar município foi Caxias do Sul, seguida por Bento Gonçalves e somente dez anos depois Garibaldi. Já Silveira Martins teve seu território retalhado e distribuído entre quatro municípios. As partes do território mais significativas na época, como a sede e núcleos mais desenvolvidos ficaram com o município de Santa Maria, outra parte ficou com Cachoeira do Sul e a outra com São Martinho, que devido a sua extinção em 1903, passa para Vila Rica, hoje Júlio de Castilhos, e por isso fala-se em quatro municípios. E é nesse momento que começa as diferenciações na evolução de Silveira Martins em relação as outras três colônias. "Nem a sede da Colônia nem os núcleos, apesar de terem alcançado bons níveis de desenvolvimento, foram capazes de articular-se para esboçar e sustentar movimentos emancipacionistas" (Santin, 1999: 15). 
Dessa forma, percebe-se que embora as quatro Colônias de Imigração tenham origens semelhantes, elas apresentaram características diferenciadas no seu desenvolvimento. Somente na década de 1950 é que os movimentos emancipacionistas tem êxito na Quarta Colônia, com a emancipação de Faxinal do Soturno e Nova Palma, distritos de Cachoeira do Sul e Julio de Castilhos. A sede da exColônia de Silveira Martins só veio a se emancipar no ano de 1987, praticamente cem anos depois da emancipação de Caxias do Sul.

Atualmente, o então município de Silveira Martins, criado com a desmembração de terras dos municípios de Faxinal do Soturno e Santa Maria, tem sua a economia baseada no setor primário, destacando-se o cultivo do arroz e da batata inglesa. O Município possui uma área de $122,7 \mathrm{Km}^{2}$, ocupada por uma população de 2.566 habitantes. Do total de habitantes do município de Silveira Martins, 1.039 habitantes residem na área urbana e 1.527 habitantes na área rural (Ibge, 2007).

Os dados até então apresentados demonstram que este Município possui uma população rural superior a urbana, e não é apenas na população que as características do rural manifestam-se como predominantes no município de Silveira Martins. Elas podem ser observadas nos modos de vida da população local, na vida pacata e tranqüila da cidade, nas relações próximas dos habitantes, nos costumes herdados dos antepassados que colonizaram a localidade, nas festividades que envolvem a comunidade e na gastronomia.

Esses elementos, que podem ser considerados manifestações das ruralidades presentes no local, vem sendo enfocados como atrativos turísticos, principalmente no que diz respeito a culinária típica e os costumes locais, como é o caso da Rota Turística e Gastronômica da qual o Município de Silveira Martins faz parte.

A atividade turística na região a qual o município de Silveira Martins encontra-se inserido teve iniciono ano de 1995 quando se criou o "Projeto de Desenvolvimento Sustentável da Quarta Colônia do RS" (Prodesus), no qual estava contido entre outros, o projeto de Desenvolvimento do Turismo Ecológico, Rural e Cultural e de Educação Ambiental. Esse projeto era parte integrante do projeto de desenvolvimento integral voltado as especificidades culturais e turísticas locais, o qual foi instituído no ano de 1995, com o apoio do Ministério do Meio Ambiente, dos Recursos Hídricos e da Amazônia Legal, o qual incentivou a criação do Consócio de Desenvolvimento Sustentável (Condesus) entre os municípios da Quarta Colônia e os municípios de Agudo e Restinga Seca.

Dessa forma o projeto de Desenvolvimento do Turismo Ecológico, Rural e Cultural e de Educação Ambiental englobou tanto os municípios pertencentes a Quarta Colônia de Imigração Italiana, quanto os outros dois municípios, aos quais o projeto propôs além da implantação de vários roteiros turísticos rurais a integração dos envolvidos, tentando promover arranjos produtivos intermunicipais. O projeto foi desenvolvido em parceria com o Serviço de Apoio ás Micro e Pequenas Empresas do Rio Grande do Sul (SEBRAE-RS) e conforme Souza (2007: 14):

\footnotetext{
"As ações do projeto de turismo visam fortalecer os arranjos produtivos locais e intermunicipais com o objetivo de capacitar e formar os dirigentes das agroindústrias, os artesãos, os floricultores, os proprietários das agências de turismo e os empreendedores que comporão os roteiros".
} 
Os roteiros religiosos integrando um ou mais municípios são os que mais destacam-se nessa Região. Esses caminhos englobam passagens por capelas, igrejas, plantações, antigos casarões, agroindústrias, enfatizam a gastronomia da Região ligada a imigração italiana, suas motivações de fé e hábitos culturais, que remontam aspectos da infância ou dos antepassados (Souza, 2007).

Nessa lógica a Rota Turística analisada neste estudo, denominada Rota Turística e Gastronômica Santa Maria-Silveira Martins (Figura 2), foi criada com o fim de valorizar o caminho percorrido pelos imigrantes italianos quando chegaram a Silveira Martins. Localizada nos dois municípios, inicia-se na VRS 511 (Arroio Grande) e termina no centro de Silveira Martins. Entre os atrativos estão capelas, igrejas, construções históricas, balneários, propriedades rurais, paisagens, cantinas e restaurantes onde são servidos pratos típicos da culinária italiana.

Figura 2 Folder de divulgação da Rota Turística e Gastronômica Santa Maria - Silveira Martins

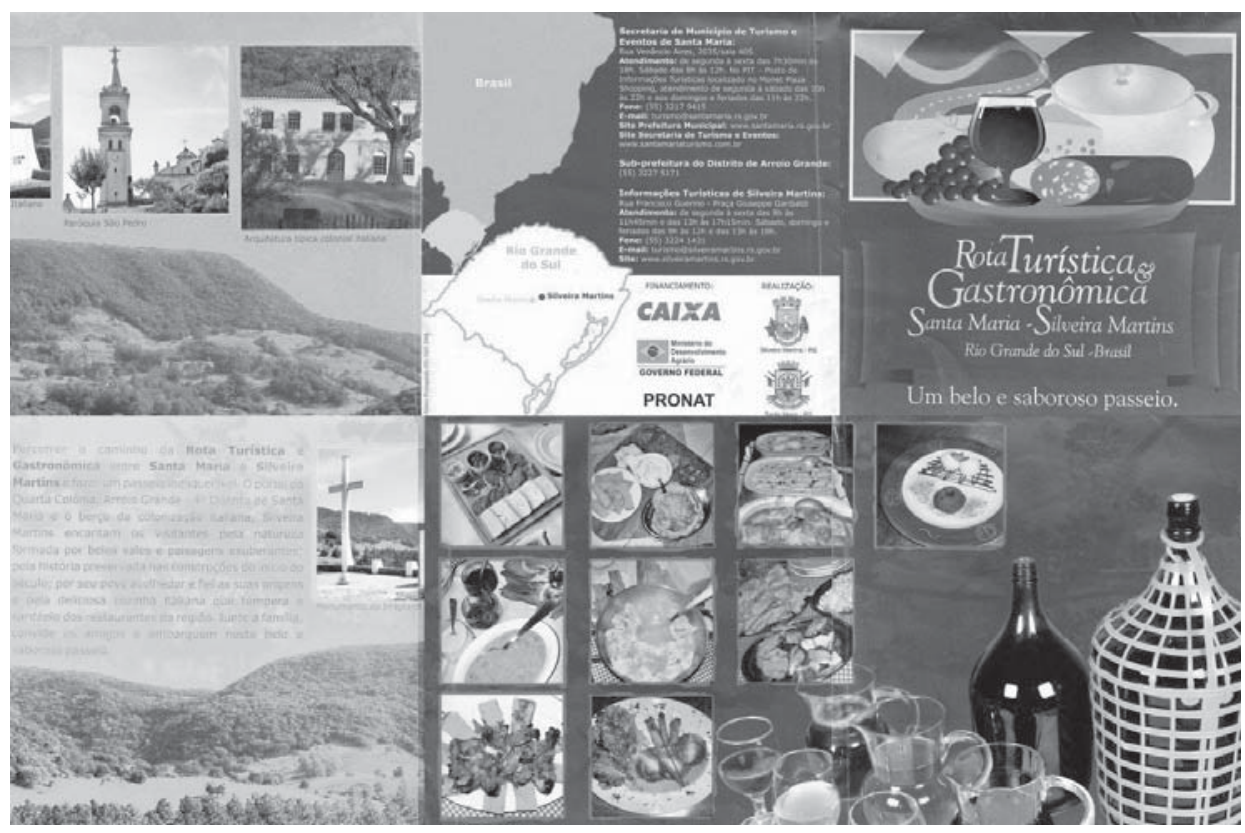

Os produtos comercializados na Rota são produtos que sofrem a influência da cultura trazida pelos descendentes de imigrantes italianos (Figura 3). Isso demonstra que estes produtos possuem uma grande carga das tradições da comunidade local, já que se trata de uma área que foi colonizada por essa etnia e até hoje sofre as influências desta colonização. Entre essas influências, ainda existe o apego às práticas produtivas tradicionais, fazendo com que sejam uma expressão dos costumes tradicionais da região e também uma manifestação das ruralidades.

Nesse sentido Schlüter (2003), coloca que diversos autores afirmam que a gastronomia de uma sociedade expressa sua estrutura de maneira inconsciente, elas geralmente 
utilizam para preparar seus pratos elementos que desenvolvem na área onde residem e apresentam afetividade e um enfoque simbólico. Dessa forma, a autora coloca que o alimento tem significado simbólico em determinadas sociedades e que sua preparação está condicionada a valores culturais e códigos sociais a partir dos quais as pessoas se desenvolvem.

Figura 3 - Produtos comercializados no município de Silveira Martins - Rio Grande do Sul, Brasil.

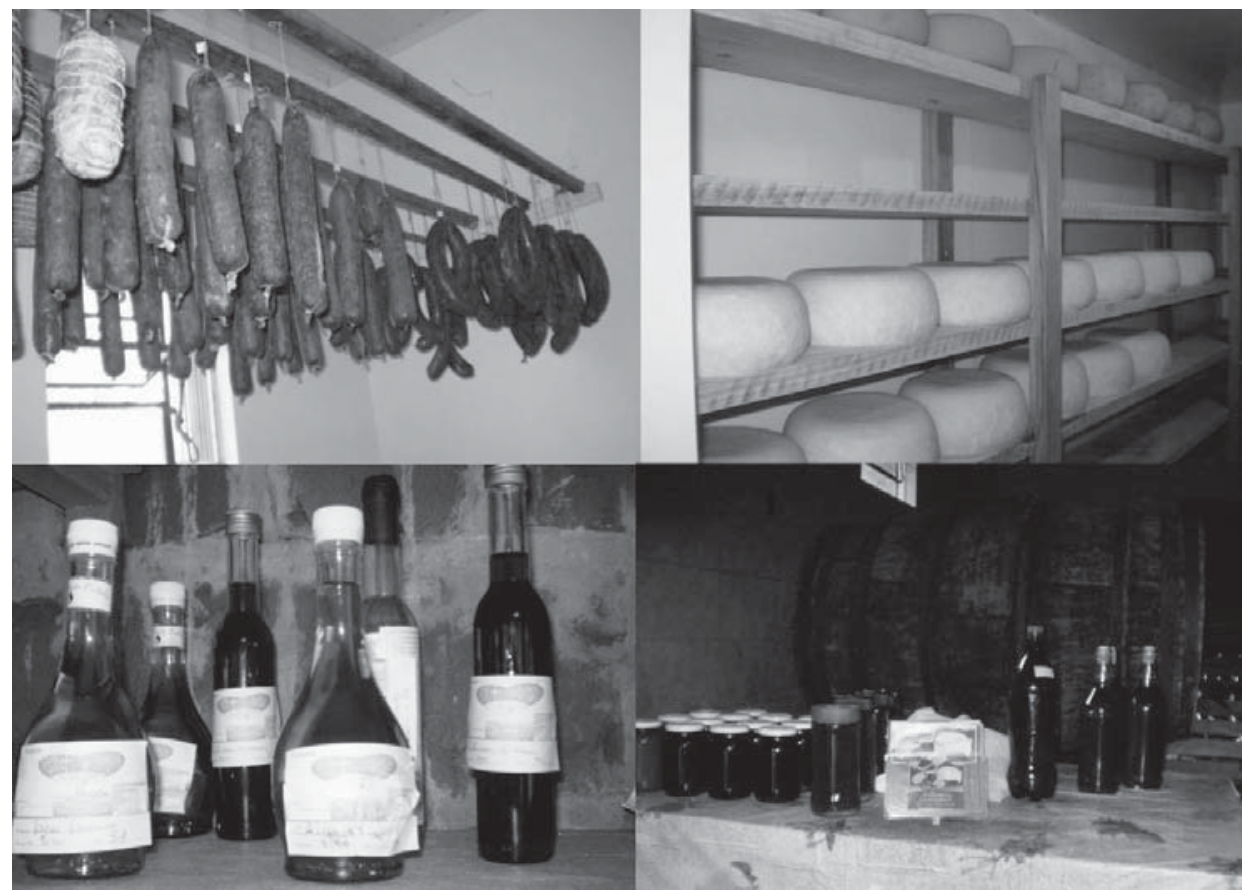

As observações de Schlüter (2003) vão ao encontro do fenômeno estudado, já que os produtos comercializados no âmbito do turismo no município de Silveira Martins têm suas matérias primas em sua grande maioria oriundas do Município ou municípios vizinhos. Dados relativos a origem dos produtos comercializados na Rota Gastronômica a qual o município de Silveira Martins faz parte, podem ser observados na Tabela 1.

Tabela 1 - Origem dos produtos comercializados nos empreendimentos da Rota Turística e Gastronômica Santa Maria - Silveira Martins

\begin{tabular}{lcc}
\hline Origem da fabricação & Variedades de produtos & $\%$ \\
\hline Propriedade onde o estabelecimento está inserido & 77 & 50,33 \\
Por vizinhos da propriedade & 4 & 2,61 \\
No Município & 42 & 27,45 \\
Em municípios da Região & 17 & 11,11 \\
Em outros Municípios & 13 & 8,5 \\
Total & $153^{*}$ & 100 \\
\hline
\end{tabular}

Fonte: Lindner, 2008. 
* Mesmas variedades de produtos foram colocadas como diferentes por terem fabricação de origens diferentes, o que fez com que o total passasse das quarenta e seis variedades de produtos existentes nos estabelecimentos da Rota.

Além disso, esses produtos possuem um grande valor simbólico, já que expressam a cultura do local. Na Rota Gastronômica, existe uma grande variedade de produtos coloniais e artesanais para a comercialização, disponíveis para os turistas nos estabelecimentos comerciais da Rota. Estes produtos e pratos tratam-se de produtos coloniais e característicos da cultura dos descendentes de imigrantes italianos, fato este que dá a identidade ao lugar e o torna atrativo aos turistas, que buscam um retorno às tradições dos antepassados que colonizaram o local.

Os produtos fazem parte da tradição das famílias que residem no Município de Silveira Martins, sendo que em pesquisa realizada no local com proprietários de restaurantes e afins, quase a metade (43\%) dos entrevistados declaram ter a produção motivada em tradições familiares, ressaltando que antes da comercialização os produtos já eram produzidos para o consumo familiar.

Outra característica marcante na Rota é o trabalho familiar, a grande maioria dos estabelecimentos comercias localiza-se na área rural do município de Silveira Martins e seus proprietários são pequenos produtores familiares, que transformam seus produtos de forma artesanal ou semi-artesanal através de pequenas agroindústrias, que utilizam mão-de-obra familiar. De maneira geral, a família trabalha na atividade turística, sendo que em $57 \%$ dos estabelecimentos não é contratada mão-de-obra adicional, ficando o trabalho por conta apenas da família do proprietário. Esse caráter familiar da recepção dos turistas representa um atrativo a mais, pois existe um contato mais próximo entre os visitantes e os receptores, podendo os primeiros vivenciar o modo de vida local.

As festividades também merecem grande destaque na exploração das ruralidades como produto turístico. No município de Silveira Martins é muito comum festas em torno de produtos alimentares, principalmente os agropecuários, como é o caso da Festa da Batata e o Festival da Uva e das Águas. Essas festas, assim como várias outras festas temáticas tem como principais atrações elementos que resgatam costumes do rural e dos antepassados que colonizaram a região.

Esses elementos podem ser verificados na mobilização da comunidade em torno das festas, onde a comunidade se une para a organização dos preparativos, trabalhando em conjunto em torno de objetivos comuns, transmitindo dessa forma a valorização da identidade local e familiar implícitas na festa.

No caso das instalações, geralmente faz-se uso de salões de festas de igrejas, tendo em seu entorno capelas, santuários, basílicas e a própria igreja da comunidade, acentuando o caráter comunitário desses eventos.

Além dos eventos festivos e estabelecimentos comerciais turísticos, a estrutura da cidade também reporta a uma vida simples e pacata, característica de áreas rurais. $\mathrm{O}$ município de Silveira Martins não possui um grande número de estabelecimentos comerciais, sendo os existentes de pequeno porte, possui transito de veículos tranqüilo, algumas carências nos sistemas de comunicação, principalmente no caso da telefonia celular. Por- 
tanto, trata-se de um pequeno município no interior do Rio Grande do Sul, que manteve e cultua as tradições de seus antepassados, apresentando fortes elementos da vida rural e que por estas características visualizou a possibilidade da exploração turística, ou seja, passou a explorar características de seu cotidiano e de seus modos de vida como um produto turístico.

\section{CONSIDERAÇÕES FINAIS}

Analisando o caso apresentado e reportando-se a muitos outros casos semelhantes existentes em pequenos municípios do interior do Brasil, percebe-se que a exploração das ruralidades como um produto turístico tem se tornado cada vez mais comum. Trata-se do resgate da cultura desses pequenos municípios que passa a se tornar atrativo para pessoas que moram em grandes e médias cidades, e vão em busca de contato com a natureza, com animais, comidas caseiras, culturas diferenciadas.

É nesse contexto, que o município de Silveira Martins, assim como os demais da Região ao qual faz parte, a Região da Quarta Colônia de Imigração Italiana, tem tentado explorar suas áreas turisticamente. Eles se valem de características locais, as quais não foram implantadas para o turismo e sim coisas cotidianas da vida dos moradores que habitam essas localidades.

A vida dessas comunidades está muito relacionada com hábitos e valores do rural tradicional. Nesses locais, tanto na área rural, como na urbana ainda existem contatos muito próximos entre seus habitantes, festividades que reúnem a comunidade, seus familiares e pessoas de municípios próximos, que geralmente possuem vínculos de parentesco ou amizade com moradores locais. Existe também um envolvimento da comunidade nas festividades, assim como a religiosidade muito presente.

Todos estes elementos podem ser considerados manifestações das ruralidades, que encontram-se implícitos nos modos de vida de pequenas comunidades rurais, elementos estes dificilmente encontrados em grandes e médias cidades, onde as relações entre os habitantes tornam-se mais distantes devido a vida agitada, a falta de tempo, a distância, entre vários outros elementos. E é nesse sentido que a vida pacata e absorvida pela cultura local de pequenos municípios torna-se um grande atrativo para pessoas que moram em cidades maiores. Portanto, esse tipo de turismo, que tem seu foco na exploração das ruralidades como atrativo, representa também uma interação rural - urbano, pois se trata de uma atividade de raiz urbana, que busca sua demanda neste local.

\section{REFERÊNCIAS BIBLIOGRÁFICAS}

Boni, L. A. de; Costa, R. (1982): Os italianos do Rio Grande do Sul. Vozes, Porto Alegre. Candiotto, L. Z. P.; Corrêa, W. K. (2008): Ruralidades, urbanidades e a tecnicização do rural no contexto do debate cidade-campo. In: CAMPO-TERRITÓRIO: revista de 
geografia agrária. http://www.campoterritorio.ig.ufu.br [Acedido em 12 de Junho de 2008].

IBGE - INSTITUTO BRASILEIRO DE GEOGRAFIA E ESTATÍSTICA (2007). Censo 2000.http://www.ibge.gov.br/censo [Acedido em 15 de Junho de 2007].

Lindner, M. (2008): O turismo na revalorização da agroindústria rural na rota gastronômica de Silveira Martins - RS. FACOS, Santa Maria.

Moreira, R. J.; Gaviria, M. R. (2002): Territorialidades, ruralidades e assimetrias de poder na Comunidade de Taquari. In: Estudos Sociedade e Agricultura. http://bibliotecavirtual.clacso.org.ar/ar/libros/brasil/cpda/estudos/dezoito/roberto18.htm [Acedido em 11 de Junho de 2008].

Portuguez, A. P. (2002): Agroturismo e Desenvolvimento Regional. Hucitec, São Paulo.

Ruviaro, R. (2007): SILVEIRA MARTINS: O Berço da Quarta Colônia de Imigração Italiana do Rio Grande do Sul.http://www.silveiramartins.rs.gov.br [Acedido em 21 de Junho de 2007].

Santin, S. (1999): Sonhos Diferenciados ou desfeitos: Silveira Martins, a Quarta Colônia, no cenário da imigração italiana no Rio Grande do Sul.In: MARIN, J. R. (org.). Quarta Colônia: novos olhares. EST, Porto Alegre.

Souza, M. de. (Org.) (2007): A demanda e as perspectivas do turismo nos municípios da Microrregião da Quarta Colônia - RS. Edital FAPERGS PROCOREDES II, Porto Alegre.

Schlüter, R. G. (2003): Gastronomia e turismo. Aleph, São Paulo.

TuliK, O. (2003): Turismo Rural. Aleph, São Paulo.

Wanderley, M. de N. B. (2001):A ruralidade no Brasil moderno. Por um pacto social pelo desenvolvimento rural.In: ¿Una nueva ruralidad en América Latina?.Buenos Aires:CLACSO. http://www.clacso.org/wwwclacso/espanol/html/libros/rural/rural.html [Acedido em 11 de Junho de 2008] 